SALMÓN, Josefa. Valor e Comunidade: Reencontro Marxista y boliviano. Uma Conversação com Álvaro García Linera. 2da Edição. La Paz (Bolívia). Vicepresidência do Estado Plurinacional da Bolívia. 83 pág. 2018.

\title{
VALOR E COMUNIDADE: REENCONTRO MARXISTA Y BOLIVIANO. UMA CONVERSAÇÃO COM ÁLVARO GARCÍA LINERA ${ }^{1}$
}

\author{
DOI: http://dx.doi.org/10.9771/gmed.v11i3.35071
}

Hander Andrés Henao ${ }^{2}$

A questão da «Comunidade» é central para o pensamento e para o campo de estudos marxista: nela se encontra um potencial para a construção da revolução no processo geral de luta de classes e na identificação do sujeito revolucionário. Uma problemática que penetra na formulação das condições de possibilidade do ser humano como das condições de possibilidade da sociedade futura e do horizonte revolucionário para alcançar o comunismo. Todos os âmbitos da existência humana são hoje campos de luta e a «Socialidade Comunitária» é uma constelação das esferas da vida humana. Sua compreensão brinda um forte potencial liberador em relação às problemáticas da nação e da etnia, configurando um debate tanto no campo teórico como no campo político.

Este livro, “Valor e Comunidade: Reencontro Marxista y Boliviano”, se vincula a esta reflexão sobre as possibilidades de liberação da «Comunidade», e propõe apresentar e entender o pensamento crítico e vivo de uma das figuras mais representativas na atualidade do marxismo e do indianismo na América Latina: Álvaro García Linera (1962). Josefa Salmón é uma boliviana especialista em estudos literários, catedrática da Universidade de New Orleans (Departament of Lenguages and Cultures), sendo seus estudos centrados ao entendimento do indianismo como discurso e sua formação histórica. Por sua vez, Álvaro García Linera é o intelectual político que se tornou político intelectual desde a chegada à presidência de Evo Morales em 2006 na Bolívia, assumindo o posto de vice-presidente; sempre atuando no âmbito dos movimentos sociais revolucionários como o EGTK (Ejército Guerillero Túpac Katari) e vinculado a uma reflexão no campo de estudos marxistas. A obra é um encontro entre os dois, uma entrevista estendida ao vice-presidente do Estado Plurinacional de Bolívia, de perguntas incisivas que permitem compreender tanto o pensamento teórico-filosófico de Linera como os fundamentos da política e a concepção da democracia socialista que se construiu nos últimos 13 anos no país andino; apresenta-se o potencial histórico de mudança da sociedade boliviana, da «Forma Comunidade» na construção do Estado Plurinacional em sua luta contra a «Sociabilidade do Valor».

O livro estrutura-se por núcleos temáticos que configuram sete capítulos e que apresentam a formação intelectual de Álvaro García Linera, aspetos biográficos e de formação, assim como sua abordagem teórica na sua mais expressiva obra: "Forma Valor e Forma Comunidade: Aproximação teórica-abstrata aos fundamentos civilizatórios do Ayllu Universal" escrito na época de seu prisão e publicado em 1995. A problemática central em toda a entrevista é entender as relações que se estabelecem entre a «Forma Valor» 
como fundamento civilizatório da modernidade e a «Comunidade» como potencial revolucionário na ruptura com esta ordem civilizatória. Nesse ponto, a abordagem de Marx às "Formas de sociabilidade" dos povos originais, ou seja, das sociedades, culturas e civilizações antigas em diferentes partes do mundo e, em particular dos povos ameríndios, torna-se realmente importante pela fundação de suas críticas ao projeto Civilização Moderna, na leitura que realiza o vice-presidente.

No primeiro capítulo a autora pergunta para Álvaro García Linera sobre seus primeiros passos na luta revolucionária, adentrando nas relações entre movimento indígena e luta armada. O vice-presidente reafirma sua obsessão política: Entender o conhecimento que possui o pensamento de Marx sobre os povos indígenas, o que falou este sobre os camponeses e da Comunidade como forma de existência social; em definitiva como Marx e o movimento indianista articulassem à luta contra o colonialismo y a colonialidade no horizonte revolucionário. A unificação entre razão e paixão na figura dum militante radical, amante da matemática e das humanidades, dum visionário da utopia concreta, faz que na sua perspectiva a teoria e a práxis entelham constantemente em tensão e determinação. A obsessão é em tudo momento e sobre qualquer circunstância, conceptual e política, um pensamento que guia a ação política e uma atividade política que da vida a um pensamento crítico.

É tanto a descrição da vida e formação política do vice-presidente como uma narração sobre os principais fatos políticos que marcaram a construção da sociedade, Estado e democracia boliviana no devir de finais do século passado para o século presente, em outras palavras, é uma narrativa, da biografia da vida de Álvaro García Linera, uma historiografia política da sociedade boliviana e uma apresentação histórica dos problemas e a obra de K. Marx no debate latino-americano. O Álvaro García Linera apresenta-se como pensamento vivo, como sujeito senti-pensate que construí o caráter objetivo de suas categorias como dinamismo duma sensibilidade crítica, que percebe o sofrimento das massas oprimidas pelo poder. A tranquilidade de suas palavras é mostra de radicalidade de suas convicções ético-políticas; os cabelos grisalhos adornam sua sabedoria teórica e sua experiência revolucionária.

No segundo e no terceiro capítulos questiona Josefa Salmón ao vice-presidente sobre um debate filosófico que é central na estratégia pela disputa da hegemonia política: as relações entre particularidade e generalidade, no âmbito do nível teórico e as relações entre localismo das disputas dos movimentos sociais e a conquista do poder do Estado na construção do horizonte revolucionário da transição à sociedade comunista, no nível político. Uma discussão clássica no pensamento político de esquerda, que coloca o ponto de ênfase no problema pelo partido revolucionário, a toma de poder do Estado e a articulação do movimento de classe junto à problemática da etnia e a nação. Um debate interno na política e no pensamento crítico no subcontinente.

A recepção das ideias de K. Marx na América Latina não apenas marca um momento importante na tradição do "marxismo", marca fortemente a história da filosofia no subcontinente, determinando o futuro das lutas políticas no nível teórico-prático. $\mathrm{Na}$ atualidade as ideias do alemão são fortemente questionadas pela tradição mais contemporânea do pensamento latino-americano, como é o pensamento descolonial. Neste ponto, sabe o Vice-presidente que entra num debate com o pensamento crítico latinoamericano, mas toma posição e marca pontos de confluência nas lutas políticas. O projeto editorial 
conduzido pela vice-presidência do Estado Plurinacional da Bolívia, por publicar na língua espanhola os textos inéditos de Marx, nos que o pensador crítico analisa as «Formas de sociabilidade» anteriores ao capitalismo e particularmente as «Formas de Sociabilidade Ameríndias», seus escritos nomeados de "Etnológicos" assim como os textos nos que Marx trata da questão agraria e do colonialismo, nos permite acessar aquele pensador crítico (Marx) que fala-nos da potência revolucionaria da «Comunidade ancestral», em contraste com as leituras descoloniais - da linha liberal - e pós-modernas. O trabalho de Álvaro García Linera é do pesquisador que propõe ir as "fontes mesmas", sem cair com isso na estatização da letra frente ao movimento histórico. Seu trabalho é uma revitalização do pensamento de Marx a dois séculos de sua nascimento, colocando sua fala al serviço da luta do movimento proletário camponês, índio e popular, do marginado latino-americano; ao mesmo tempo que coloca as lutas sócias contemporâneas ao serviço da revitalização da obra de Marx.

Nos capítulos seguintes - "Indícios da lógica comunitária na relação hombre-naturaleza" e "Outras aposições as "comunidades" de Marx" - centra-se na antropologia materialista, na abordagem deste horizonte filosóficopolítico das «formas de Sociabilidade Ameríndias». Produz-se um giro nas discussões, pois os aportes de Álvaro García Linera na tradição do marxismo são impressionantes e de uma atualidade conjuntural de vanguarda na imanência das lutas de classes na região latino-americana. O debate com a ortodoxia da segunda internacional e com os mais canônicos leitores da obra de Karl Marx (1818-1883) como Eric Hobsbawm (1917-2012), Lawrence Krader (1919-1998), Roman Rosdolsky (1898-1967), Karl Kautsky (1854-1938) e até o próprio F. Engels (1820-1895) - debate quente na tradição do pensamento comunista como um todo, pelas suas implicâncias políticas- faz com que o pensamento do vice-presidente se inscreva de maneira contundente na história desta corrente pela originalidade de sua leitura.

A essa altura a entrevista permite ver como o pensamento de Álvaro García Linera, nas suas leituras da obra de Marx desde a vida e formas sociais ancestrais, as relações entre a formulação de sua antropologia filosófica, sua crítica à economia política e seus estudos etnológicos, demonstra como Marx enxerga as diferentes maneiras de compreender os processos de desenvolvimento da sociedade na construção duma crítica radical à racionalidade civilizatória da modernidade. O horizonte é superar não só o domínio econômico do capital se não da civilização do capital como um todo. O intuito de mergulhar no pensamento de Marx - num claro trabalho filológico e exegético, numa hermenêutica crítica e materialista - para encontrar sua abordagem da relação comunitária como «Formas de Sociabilidade», nestes capítulos (quarto e quinto) se condensa numa apresentação da potência revolucionária na questão da «Comunidade» e sua relação com a «Civilização do Valor». As relações estabelecidas por Marx (2011, p. 147) entre o processo de «Produção» e o processo de «Circulação» mostram uma série de recíprocas contradições ${ }^{3}$ que constroem as condições para a possibilidade do relacionamento social do Capital (que surge no processo de Produção), ao mesmo tempo em que existe "anteriormente" um relacionamento de Classe (manifestado anteriormente na Lei da Circulação) que determina a existência de referida relação social, indicando os processos de tráfego do abstrato ao concreto.

A antropologia materialista de Marx, na leitura de Álvaro García Linera, mostra que as relações entre ser humano e natureza podem ser de outro tipo, que existe um potencial comunitário na própria 
constituição da humanidade, fundamento de um intercambio orgânico entre ambos. O problema pela civilização mostra um Marx crítico do "eurocentrismo" e na procura de alternativas de existência social. Longe de propor uma receita de evolução humana, Marx mostra a diversidade e hetegoneidade da atualização das condiciones do fenômeno humano no mundo, a diversidade de povos e culturas, embora o fez dando luz sobre o caráter universal da forma comunidade frente à universalização da forma valor que subsome aquela forma ao princípio do valor de cambio e a valorização do valor. Os cinco modos de produção existentes (Comunismo primitivo, escravista, feudal, capitalista y socialista) não se sucedem de forma linear em todo o mundo; pelo contrário existe as mais variadas maneiras de sua concretização segundo os povos e as culturas, sendo este fato as possibilidades concretas do "comunismo futuro". Nessa ordem, é possível uma transição ao comunismo sem a necessidade da extinção das formas comunitárias, posto que elas são uma clave revolucionaria do cambio social. Nos argumentos do Vice-presidente García Linera fica claro sua toma de posição pelo potencial emancipador das «formas de Sociabilidade Ameríndias» e a construção do Estado Plurinacional boliviano no horizonte de novas alternativas civilizatórias, a necessidade de superar a ordem econômica do capitalismo, adentrando-se nos conhecimentos e formas de sentido e práxis da comunidade ancestral.

Finalmente, os últimos dois capítulos retornam da concretude-pensada desde o debate teórico aos temas políticos na conjuntura do processo de construção do Estado Plurinacional, na formação de uma sociedade socialista centrada na relação de «Comunidade» fortemente prevalecente na cotidianidade índia na Bolívia. Transitam-se do âmbito de uma antropologia general do potencial transformador da relação de «Comunidade» a suas concretizações na sociedade Boliviana, suas possibilidades e dificuldades. Nesta última parte, fica claro na conversa entre Josefa Salmón e Álvaro García Linera que a «luta de classes» é motor da história no pensamento de Marx porque o antagonismo entre os grupos sociais sintetiza o processo contraditório da construção das fontes do poder social (religioso, econômico, político) e articula-se ao processo geral de trabalho social que sustenta um processo civilizatório que é o objeto de crítica, não sendo assim uma "metafísica da história" mas sim uma crítica da historicidade social. As relações entre sindicato e «Comunidade», por exemplo, é uma digressão que serve ao Vice-presidente para mostrar um pouco a realidade e fundamento de seu pensar e formação teórica, na sua própria experiência como dirigente das lutas sociais e como reflexo do problema teórico de organização revolucionaria, apontando do mesmo modo a construção do "sujeito revolucionário comunitário", nas relações entre etnia-classe e entre comunidadeorganização política.

A reconfiguração da soberania política do Estado a partir dum processo de "descolonização comunitária" do monopólio do poder via democratização das decisões no movimento social, colocam a premissa da solução desta dicotomia no caráter real da disputa imanente pelo poder, no caráter histórico do movimento da correlação de forças e ao Movimento Al Socialismo MAS como a forma organizativa e revolucionaria que agrupa as mais variadas identidades plebeias.

A apertura das possibilidades sociais para uma nova classe média integrada pelos sectores antigamente marginalizados, demostra a democratização do poder e a descolonização do Estado graças à aceitação do caráter pluriétnico do povo, construído outras formas de gerenciar os recursos públicos. Uma 
nova lógica do Estado, que imprime no interior as formas comunitárias de gestão da vida coletiva, de produção e distribuição dos recursos. No entanto, aqueles avanços mantem a tensão entre monopólio do poder por parte do Estado e autonomia do movimento social. "Se tem que viver a contradição" diz o político intelectual, porque no nível da discussão teórico e ideológica, o intelectual já se sabe um político revolucionário, se tem que buscar um equilíbrio, dar maior dinamismo a relação, sabendo que o movimento social tem a batuta, o Estado tem que tomar sua forma comunitária. O Estado não se separa da sociedade, o movimento social se apropria da totalidade, recupera seu ser de gênero.

$\mathrm{Da}$ "Guerra pela agua", "a chegada ao Poder", "o referendum de 2008 e o intento de Golpe de Estado" ao "Processo Constituinte" manifesta-se a construção do Estado Plurinacional também como um processo de lutas historias, derrotas, vitorias, uma disputa dinâmica entre as elites tradicionais, os grupos e movimentos sociais e os partidos políticos no contexto dos movimentos dos ciclos do capital.. É pelo movimento objetivo das relações histórico-sociais que se establece uma relação antagônica entre «classes», cuja razão de ser situa-se no horizonte das "Tendências históricas objetivas" gerais do devir no proceso do trabalho social. Desse modo, na concepção de uma crítica materialista do poder, o Estado, na Bolívia, é a realização do poder social, a disputa pela hegemonia daqueles que têm a capacidade de por em movimento o processo de circulação das mercadorias e com ele, a produção da mais- valia na circulação mundial e na exploração do trabalho; uma classe branca e mestiça, frente à população das comunidades índias; portanto, o Estado e sua transformação, é um campo de disputa.

Os acontecimentos do último mês, após as eleições presidenciais do dia vinte (20) de outubro na Bolívia, desencadearam uma série de mobilizações reacionárias ao reiterado triunfo de Evo Morales, demostram que longe de qualquer fim da história, estamos entrando em um novo ciclo de lutas e reconstrução de sociedades e Estados em todo o mundo. América Latina e as formas Comunitárias inscritas nas suas sociedades originarias voltam a ser centrais. O novo ciclo de lutas político-econômicas da região é marcado pela constante disputa de hegemonia por métodos convencionais e não convencionais, atualizando a forma de disputa com uma série de golpes legislativos - Honduras 2009, Paraguai 2012 e Brasil em 2016 -, e "golpes diplomáticos" amparados na construção do Grupo Lima, o papel da OEA nos processos de autoproclamação de títeres e paladinos políticos ao serviço dos interesses do capital imperialista na região latino-americana. O que foi um intento na Venezuela se consuma hoje na Bolívia. Ambos os processos revolucionários e contrarrevolucionários têm suas particularidades.

O central desta segunda edição do diálogo entre Josefa Salmón e Álvaro García Linera em 2014, é que nos permite compreender o enfoque fundamental da construção do processo revolucionário na Bolívia, introduzindo o pensamento crítico de Álvaro García Linera ao mesmo tempo em que nos permite pensar os equívocos, também pontuando os acertos na retomada política frente ao golpe e o avanço imperialista na região. A leitura desse livro tem uma contemporaneidade tanto teórica quanto política. $\mathrm{O}$ texto não é apenas uma aproximação ao pensamento de Marx e sua análise das comunidades, mas também um caminho para aprofundar no pensamento político de Álvaro García Linera, encontrando nele os fundamentos próprios para uma leitura crítica do processo político-social boliviano em sua atual conjuntura de crises. 
A pertinente leitura da obra de Marx que realiza o vice-presidente Linera, demostra o perigo de tal projeto de sociedade para os interesses da "civilização do valor". O vice-presidente demostra que Marx constrói uma crítica radical ao projeto da civilização moderna, concentrando-se nas críticas ao modo de produção capitalista, pois dá "Forma" à existência histórica de um modo específico de existência de uma "Sociabilidade" humana.

O ciclo da capital e o ciclo político na Bolívia condicionam as atuais correlações de forças no processo revolucionário. Com a certeza do potencial transformador da «Comunidade», esta entrevista permite-nos então seguir no caminho de um pensamento e duma prática revolucionária. Romper com esse ciclo histórico depende de retomar a rebelião ancestral. O pensamento vivo de Álvaro García Linera demostra que hoje a esquerda deve radicalizar com o retorno das formas originais (arcaicas originais) de vida social, luta e resistência, se pretende preservar seu impulso libertador.

\section{Notas}

${ }^{1}$ Pode aceder ao registro visual da entrevista por o seguinte enlace: https://www.youtube.com/watch?v=xX9Iz0PDllo

2 Estudante de sociologia do departamento de sociologia da Faculdade de Ciências Sociais e Humanas da UdeA [nativo]. Estudante de filosofia da universidade federal de integração latino-americana UNILA (Brasil). Membro do grupo de pesquisa em Filosofia Política da Linha de Teoria Crítica do Instituto de Filosofia da Universidade de Antioquia y del Núcleo Estudos Políticos José Antonio Jimenez Comín ORCID: http://orcid.org/0000-0001-9606-7450 E-mail: sociologiadialectica11@gmail.com

${ }^{3}$ Cf conjuntamente El Capital Tomo I. Proceso de Producción. Fondo de Cultura Económica. México, 2011. Cap. V y Manuscritos económicofilosóficos. São Paulo: Boitempo, 2008, Manuscrito III. 